\begin{tabular}{|cc}
\hline KeB UnMUL & K N E R J A 15 (2), 2018 76-81 \\
http://journal.feb.unmul.ac.id/index.php/KINERJA
\end{tabular}

\title{
Analisis visi dan misi fakultas ekonomi dan bisnis universitas mulawarman
}

\author{
Rio Haribowo \\ Fakultas Ekonomi dan Bisnis Universitas Mulawarman, Samarinda. \\ Email: rio.hariwibowo@feb.unmul.ac.id
}

\begin{abstract}
Abstrak
Penelitian mengenai Analisis Visi dan Misi Fakultas Ekonomi Dan Bisnis Universitas Mulawarman yang dilakukan bulan November 2016. Visi memiliki peran penting bagi organisasi demi menyukseskan dan kelestarian organisasi atau perusahaan dalam jangka panjang dan misi digunakan sebagai petunjuk arah dalam dunia bisnis. Penelitian ini bertujuan untuk menguji apakah Misi Fakultas Ekonomi dan Bisnis Uiversitas Mulawarman masih sesuai dengan kondisi sekarang. Populasi dalam penelitian ini adalah mahasiswa Fakultas Ekonomi dan Bisnis di Universitas Mulawarman Samarinda. Pendekatan penelitian yang digunakan adalah pendekatan Kuantitatif dengan metode pengambilan sample dengan jumlah 1.730 Responden. Variabel dalam penelitian ini adalah 9 Misi Fakultas Ekonomi dan Bisnis Universitas Mulawarman sebagai variabel terikat. Pengujian Hipotesis yang digunakan adalah uji Q Cochran setelah itu di bandingkan dengan uji Chi Square Tabel. Hasil penelitian diketahui bahwa misi Fakultas nomor 2 "Menjadikan fakultas ekonomi sebagai world class faculty" dan nomor 8 "Menjalin kemajuan bersama stockholder" tidak cocok lagi menjadi misi dari Fakultas Ekonomi dan Bisnis Universitas Mulawarman di tahun yang akan datang. Berdasarkan simpulan hasil penelitian, maka penulis menyarankan untuk mengganti misi atau mempertahankan dengan cara meningkatkannya, karena hasil Q hitung $<$ Q table yaitu 12,40 $<12,59$.
\end{abstract}

Kata Kunci : atribut; misi; cochran

\section{Analysis vision and mission faculty of economics and business mulawarman university}

\begin{abstract}
Research on Vision and Missions Analysis Faculty of Economics and Business Mulawarman University conducted in November 2016. Vision has an important role for the organization for the sake of success and sustainability of organizations or companies in the long term and the mission is used as a direction in the business world. This study aims to examine whether the Missions Faculty of Economics and Business Mulawarman University still in accordance with the current conditions. Population in this research is student of Faculty of Economics and Business at Mulawarman University of Samarinda. The research approach used is Quantitative approach with the method of sampling with the number of 1730 Respondents. The variables in this research are 9 Missions of Faculty of Economics and Business of Mulawarman University as dependent variable. Testing Hypothesis used is $Q$ Cochran test after that in comparison with Chi Square test table. The results of the research note that the mission of Faculty number 2 "Making the faculty of economics as world class faculty" and number 8 "Making progress together stockholder" NOT relevant fit into the mission of the Faculty of Economics and Business Mulawarman University in the coming year. Based on the conclusion of the research results, the authors suggest to replace the mission or maintain by increasing it, because the $Q$ count $<Q$ table is $12.40<12.59$.
\end{abstract}

Keywords: attributes; mission; cochran 


\section{PENDAHULUAN}

Pada saat ini perguruan tinggi mempunyai pendidikan pada jenjang yang lebih tinggi daripada pendidikan menengah dijalur sekolah. Perguruan tinggi disini adalah tingkatan universitas yang terdiri atas sejumlah fakultas yang menyelenggarakan pendidikan akademik dan/atau profesional dalam sejumlah disiplin ilmu tertentu (H. Bashir Barthos,12:25). Dan pada saat ini perguruan tinggi haruslah dituntut untuk menciptakan lulusan perguruan tinggi yang unggul dan kompetitif dalam berkinerja, sehingga dapat bertahan (survive) dan berkembang untuk mencapai aktualisasi keunggulan secara optimal.

Universitas Mulawarman atau yang disingkat Unmul, adalah sebuah perguruan tinggi negeri yang berada di kota Samarinda, Kalimantan Timur, Indonesia. Universitas ini berdiri pada tanggal 27 September 1962 yang merupakan universitas tertua di Kalimantan Timur. Universitas Mulawarman merupakan perguruan tinggi dengan jumlah mahasiswa terbesar di Kalimantan, dengan jumlah mahasiswa mencapai lebih dari 37.000 orang. Universitas Mulawarman terdiri dari 14 fakultas didalamnya. Salah satunya adalah Fakultas Ekonomi dan Bisinis.

Universitas Mulawarman Samarinda didirikan pada tanggal 14 Mei 1966 berdasarkan Surat Keputusan Menteri PTIP No. 12 Tahun 1966. Untuk menghasilkan lulusan yang memiliki daya saing dan berkiprah di dalam bidang ekonomi maka Fakultas Ekonomi dan Bisnis mempunyai visi dan misi.

Visi dari Fakultas Ekonomi dan Bisnis universitas mulawarman adalah "Menjadikan Fakultas Ekonomi dan Bisnis berstandar internasional yang mampu berperan dalam pembangunan bangsa melalui Pendidikan, Penelitian dan Pengabdian pada masyakarat dibidang ekonomi Fakultas Ekonomi dan Bisnis yang bertumpu pada Sumber daya alam dan lingkungannya".

Misi dari Fakultas Ekonomi dan Bisnis Universitas Mulawarman adalah:

Menjadikan sebagai lembaga pendidikan tinggi yang berkualitas dalam rangka mencerdaskan dan memperdayakan kehidupan bangsa, serta memelihara integritas Nasional.

Menjadikan sebagai World Class Faculty.

Meningkatkan kompetensi Dosen dan Tenaga Akademik ke jenjang lebih tinggi.

Menghasilkan lulusan yang berkualitas dan profesional dibidang ekonomi dan bisnis, berjiwa Entepreneur serta memiliki kecerdasan intelektual, emosional dan spiritual.

Menyelenggarakan penelitian dan pengabdian pada masyarakat dibidang ekonomi dan bisnis sesuai dengan kebutuhan lokal, Nasional dan Internasional.

Menyelenggarakan dan mengembangkan dan mengembangkan pengelolaan yang efektif, efisien dan akuntabel.

Menyediakan sarana dan prasarana sesuai dengan kemajuan teknologi dan pelayanan prima.

Menjalin kerjasama kepada semua stakeholder.

Mendukung perkembangan martabat Bangsa Indonesia melalui penciptaan karya dibidang ilmu ekonomi dan bisnis yang bermanfaat bagi kemajuan Bangsa.

Dari visi dan misi Fakultas Ekonomi dan Bisnis ini maka kami ingin mengetahui apakah misimisi tersebut masih sesuai dengan kondisi dan perkembangan Fakultas Ekonomi dan Bisnis saat ini dengan menggunakan uji coba metode Cochran. Sehingga dapat diketahui misi tersebut masih relevan untuk digunakan pada masa yang akan datang.

\section{Tinjauan Pustaka}

\section{Perguruan Tinggi}

Perguruan tinggi merupakan kelanjutan pendidikan menengah yang diselenggarakan untuk mempersiapkan peserta didik untuk menjadi anggota masyarakat yang memiliki kemampuan akademis dan profesional yang dapat menerapkan, mengembangkan dan menciptakan ilmu pengetahuan, teknologi dan kesenian (UU 2 tahun 1989, pasal 16, ayat (1)).

Perguruan tinggi memiliki tiga fungsi utama, yaitu:

Pengembangan sumber daya manusia (human resource development).

Pengembangan sains dan teknologi.

Sebagai agen perubahan sosial. (Mohammad Ali, 2009: 177). 


\section{Visi dan Misi}

Wibisono (2006: 43), visi adalah serangkaian kata-kata bahkan rangkaian kalimat mengungkapkan impian, cita-cita, rencana, harapan sebuah perkumpulan, perusahaan, organisasi yang ingin dicapai di masa mendatang. Visi juga dapat dikatakan sebagai sesuatu yang sangat dibutuhkan untuk organisasi demi menjamin kesuksesan dan kelestarian organisasi/ perusahaan jangka panjang. Dengan kata lain dapat diekspresikan visi merupakan 'want to be' dari perkumpulan, perusahaan ataupun organisasi.

Wheelen (dikutip oleh Wibisono, 2006: 46-47), menyatakan misi adalah untaian kalimat yang berisi tujuan dan alasan keberadaan suatu organisasi yang memuat apa yang disediakan oleh perusahaan/ organisasi kepada masyarakat, berupa produk dan ajsa. Misi dapat digunakan sebagai petunjuk arah dalam dunia bisnis sekarang. Adapun tujuan dari pengikraran misi adalah menyampaikan kepada stakeholder, dalm organisasi maupun luar, berisi tentang latar belakang berdirinya perusahaan, arah dan tujuan perusahaan. Penggunaan satu bahasa dan komitmen yang mudah dipahami dan dirasakan kegunaannya oleh semua pihak yang terkait seharusnya merupakan pernyatan misi yang bagus dan efektif.

\section{Kerangka Pemikiran}

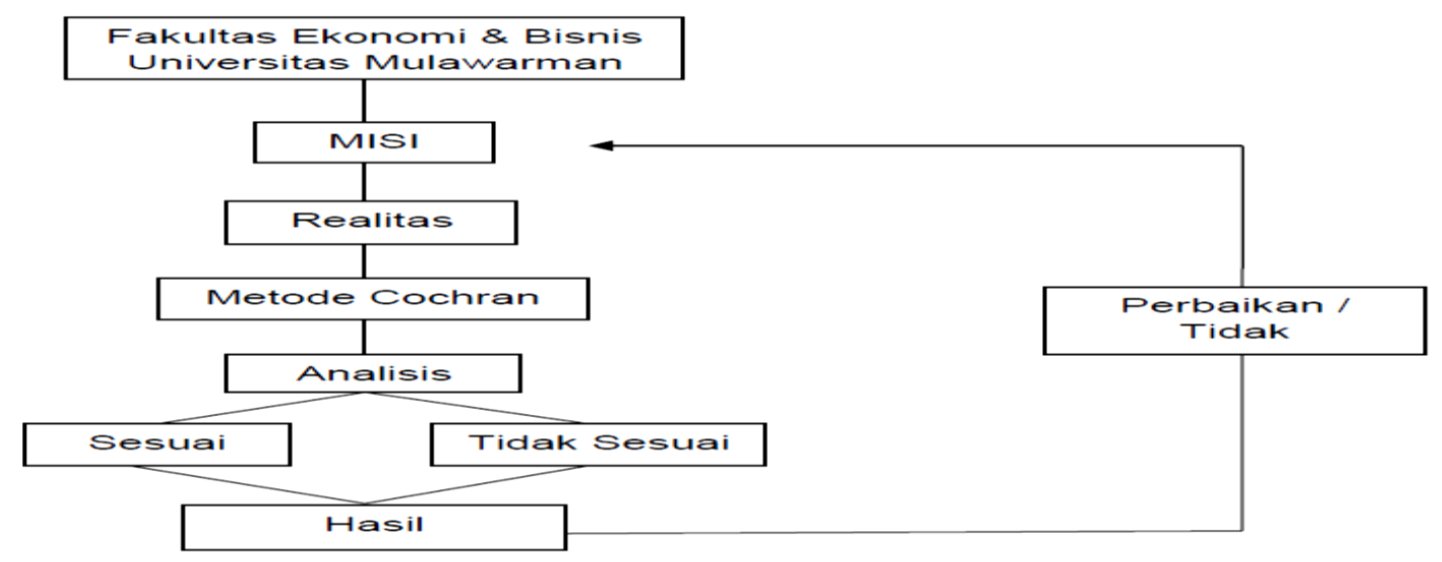

Gambar 1. Kerangka Pemikiran

\section{METODE}

\section{Populasi dan Sampel}

Populasi adalah unsur-unsur survey yang memiliki spesifikasi tertentu (Slamet, 2001:2). Populasi dalam penelitian ini adalah mahasiswa Fakultas Ekonomi dan Bisnis Universitas Mulawarman yang masih aktif mengikuti perkuliahan dan belum menyelesaikan pendidikannya di Fakultas Ekonomi dan Bisnis Universitas Mulawarman.

Sampel adalah sebagian atau wakil populasi yang diteliti (Arikunto, 2006:131). Sampel dalam penelitian ini adalah 1.730 orang mahasiswa.

\section{Jenis dan Metode Pengumpulan Data}

Sumber data yang digunakan adalah data primer. Data primer dibutuhkan oleh peneliti dari hasil wawancara kepada responden dengan bantuan kuesioner yang berisikan sejumlah pertanyaan terstruktur yang berhubungan dengan variabel yang ingin diteliti dalam penelitian (Bungin, 2005:119). Data primer ini diperoleh melalui kuesioner yang diisi oleh mahasiswa/i Fakultas Ekonomi dan Bisnis.

\section{Variabel Yang Diteliti}

Terdapat sembilan variabel dalam penelitian ini yaitu :

Menjadikan Fakutas Ekonomi dan Bisnis sebagai lembaga Pendidikan Tinggi yang berkualitas dalam rangka mencerdaskan dan memperdayakan kehidupan bangsa, serta memelihara integritas nasional;

Mejadikan Fakultas Ekonomi dan Bisnis sebagai World Class Faculty;

Meningkatkan kompetensi Dosen dan Tenaga Akademik ke jenjang yang lebih tinggi;

Menghasilkan lulusan yang berkualitas dan profesional dibidang ekonomi dan bisnis, berjiwa entrepreneur serta memiliki kecerdasan intelektual, emosional, dan spiritural; 
Menyelenggarakan penelitian dan pengabdian pada masyarakat dibidang ekonomi dan bisnis sesuai dengan kebutuhan lokal dan internasional;

Menyelenggarakan dan mengembangkan pengelolaan Fakultas Ekonomi dan Bisnis yang efektif, efisien dan akuntabel;

Menyediakan sarana dan prasarana sesuai dengan kemajuan teknologi dan pelayanan prima;

Menjalin kerjasama dengan semua stakeholder;

Mendukung perkembangan martabat Bangsa Indonesia melalui penciptaan karya dibidang ilmu ekonomi dan bisnis yang bermanfaat bagi kemajuan bangsa.

\section{HASIL DAN PEMBAHASAN}

Uji Q Cochran pada suatu penelitian hanya dinyatakan dengan salah satu dari dua nilai, atau dapat dinyatakan dengan nilai 1 sebagai "sukses" dan nilai 0 sebagai "gagal". Reaksi yang lain dapat berupa nilai 1 sebagai "ya" ataupun nilai 0 sebagai "tidak". Menurut Simamora (2004), Cochran Q-test digunakan untuk menganalisis tingkat keberha-silan/kesuksesan data secara statistik, menguji hipotesa pada beberapa variabel yang berhubungan secara diktomi yang memiliki nilai mean yang sama. Metode ini digunakan untuk menghitung data variabel Brand Image yang mencantumkan lebih dari dua atribut yang berhubungan dan masing-masing atribut terpisah menjadi dua alternatif, yaitu "ya" atau "tidak".

Uji Cochran Q-test dilakukan dengan prosedur sebagai berikut:

Menentukan Hipotesis yang diuji, yaitu:

$\mathrm{HO}$ : Semua atribut yang diuji dipertimbangkan oleh seluruh responden.

$\mathrm{Ha}$ : Semua atribut yang diuji tidak dipertimbangkan oleh responden.

Mencari Q Hitung dengan rumus sebagai berikut:

Dimana:

$$
\text { Qhit: } \frac{(k-1)\left[k \sum_{i}^{k} C_{1}^{2}-\left(\sum_{i}^{k} C_{i}\right)\right]}{k \sum_{i}^{n} R_{1}-\sum_{i}^{n} R_{1}^{2}}
$$

$\mathrm{K}=$ Jumlah Atribut yang diuji

C1 = Jumlah skor atribut $\mathrm{i}$

$R 1 \quad=$ Jumlah skor responden $\mathrm{i}$

Penentuan Chi Square Tabel (Q Tabel) dengan $\alpha=5 \%$ (0.05) maka dapat diperoleh Chi Square dari tabel distribusi Chi Square

Keputusan :

Tolak Ho dan terima Ha, jika Q Hitung > Q Tabel

Terima Ho dan tolak Ha, jika Q hitung < Q Tabel

Menentukan Q Hitung

Jumlah atribut yang akan di uji adalah sembilan atribut. Dengan standar chisquare table (Q Tabel) sebesar 15,51 hasil dari perhitungan Cochran (CO9) sebesar 42,951 dengan perhitungan sebagai berikut:

Tabel 1. Hasil kuisioner:

\begin{tabular}{clccc}
\hline No & \multicolumn{1}{c}{ Atribut } & Ya (1) & Tidak (0) & $(1)^{2}$ \\
\hline 1 & $\begin{array}{l}\text { Menjadikan Fakultas Ekonomi dan Bisnis sebagai lembaga pendidikan } \\
\text { tingggi yang berkualitas dalam rangka mencerdaskan dan } \\
\text { memberdayakan kehidupan bangsa, serta memelihara integritas } \\
\text { nasional. }\end{array}$ & 235 & 1 & 55225 \\
\hline 2 & Menjadikan Fakultas Ekonomi dan Binis sebagai world class faculty. & 140 & 96 & 19600 \\
\hline 3 & $\begin{array}{l}\text { Meningkatkan kompetisi dosen dan tenaga akademik ke jenjang yang } \\
\text { lebih tinggi. }\end{array}$ & 210 & 26 & 44100 \\
\hline 4 & $\begin{array}{l}\text { Menghasilkan lulusan yang berkualitas dan professional dibidang } \\
\text { ekonomi dan bisnis, berjiwa entrepreneur serta memiliki kecerdasan } \\
\text { intelektual, emosional dan spiritual. }\end{array}$ & 216 & 20 & 46656 \\
\hline 5 & $\begin{array}{l}\text { Menyelenggarakan penilitian dan pengabdian pada masyarakat } \\
\text { dibidang ekonomi dan bisnis sesuai dengan kebutuhan local, Nasional } \\
\text { dan Internasional. }\end{array}$ & 197 & 59 & 38809 \\
\hline 6 & $\begin{array}{l}\text { Menyelenggarakan dan mengembangan dan mengebangkan } \\
\text { pengelolaan yang efektif, efesien dan akuntabel. }\end{array}$ & 205 & 31 \\
\hline
\end{tabular}




\begin{tabular}{lllll}
\hline 7 & $\begin{array}{l}\text { Menyediakan sarana dan prasarana sesuai dengan kemajuan teknologi } \\
\text { dan pelayanan prima. }\end{array}$ & 164 & 72 & 26896 \\
\hline 8 & Menjalin kemajuan kepada semua stakeholder & 146 & 90 & 21316 \\
\hline $\begin{array}{l}\text { Mendukung perkembangan martabat bangsa } \\
\text { penciptaan karya dibidang ilmu ekonomi dan bisnis yang bermanfaat } \\
\text { bagi kemajuan Bangsa. }\end{array}$ & 217 & 19 & 47089 \\
\hline Jumlah & 1730 & - & 341716 \\
\hline Sumber: Data diolah & \\
$C o_{9}=\frac{(k-1)\left[k \sum_{i}^{k} C_{1}^{2}-\left(\sum_{i}^{k} C_{i}\right)\right]}{k \sum_{i}^{n} R_{1}-\sum_{i}^{n} R_{1}^{2}}$ \\
$=\frac{(9-1)\left[(9 \times 341716)-(1730)^{2)}\right.}{(9 x 1730)-\left(\frac{341716}{1730}\right)}$ \\
$=\frac{8 x(3075444-2992900)}{15570-197,523}$ \\
$=\frac{8 x 82544}{15372,477}$ \\
$=\frac{660352}{15372,477}$
\end{tabular}

\section{Qhit $=42,96$, Sehingga Qhit $>$ Chi Square Tabel $(42,96>15,51)$}

Dapat dilihat dari perhitungan di atas bahwa Q hitungan lebih besar daripada Chi Square Tabel, untuk itu dihitung kembali Q hitungannya dengan mengurangkan atribut yang memiliki perolehan jawaban "YA" paling sedikit pertama yaitu atribut nomor 2 "Menjadikan fakultas ekonomi sebagai world class faculty" sejumlah 140 responden, setelah dikurangi atribut nomor 2 maka kembali dihitung Q hitungnya, dimana Chi Square Tabelnya adalah 14,07 ( standar error $=0.05 / 5 \%$ ) dengan nilai $k=8$, maka diperoleh Qhit $>$ Chi Square Tabel $(27,30>14,07)$.

Dari hasil pengurangan perolehan jawaban "YA" paling sedikit pertama yaitu atribut nomor 2 diperoleh Qhitungnya lebih besar dari Chi Square Tabel (Qhit > Chi Squere tabel) maka harus kembali mengurangkan atribut yang memiliki perolehan jawaban "YA" terkecil kedua yaitu atribut nomor 8 "Menjalin kemajuan kepada semua stakeholder" sejumlah 146 responden hingga diperoleh Qhitung lebih kecil dari Chi Square Tabel (Qhit < Chi Square Tabel). Dari perhitungan perolehan jawaban "YA" paling sedikit kedua (atribut nomor 8) maka kembali dihitung Qhitungnya, dimana Chi Square Tabelnya adalah 12,59 ( standar error $=0.05 / 5 \%$ ) dengan nilai $k=7$, maka diperoleh Qhit $<$ Chi Square Tabel $(12,40<12,59)$.

\section{SIMPULAN}

Setelah melakukan uji Cochran kembali dengan mengkurangkan atribut misi yang memiliki paling sedikit perolehan jawaban "YA" yang kedua yaitu atribut nomor 8 "Menjalin kemajuan kepada semua stakeholder" sejumlah 146, maka kembali dihitung Qhitungnya, dimana Chi Square Tabelnya adalah 12,59 ( standar error $=0.05 / 5 \%$ ) dengan nilai $k=7$, maka diperopeh Qhit $<$ Chi Square Tabel ( $12,40<12,59)$ karena nilai Cochran lebih kecil dari pada nilai chi square tabel maka dapat disimpulkan bahwa atribut / misi nomor 2 dari Fakultas Ekonomi yaitu " Menjadikan fakultas ekonomi sebagai world class faculty" dan misi nomor 8 "Menjalin kemajuan kepada semua stakeholder" menurut responden tidak lagi relevan atau cocok untuk menjadi misi Fakultas Ekonomi dan Bisnis sesuai dengan kondisi saat ini. Sedangkan misi 1,3,4,5,6,7 dan 9 masih cocok atau relevan digunakan sebagai misi Fakultas Ekonomi dan Bisnis Universitas Mulawarman sesuai dengan kondisi saat ini.

\section{DAFTAR PUSTAKA}


Heizer, Jay. 2015. Operation Research, Edisi 11. Salemba Empat, Jakarta

Cochran, William G. 2010. Teknik Penarikan Sampel. Edisi Ketiga.Jakarta: Universitas Indonesia. Slamet, 2001. Teknik Pengambilan Sampel, Pabelan,Surakarta.

Suharsimi, Arikunto. 2006. Prosedur Penelitian (Suatu Pendekatan Praktik): Jakarta: Rineka Cipta. Bungin, M Burhan. 2005. Metode Penelitian Kuantitatif. Jakarta: Prenada Media Siswanto, 2007. Operation Research, Jilid Dua. Erlangga, Jakarta.

http://www.pakmono.com/2015/03/pengertian-visi-dan-misi-menurut-para-ahli.html 